\title{
Determination of Total Polyphenols and Antioxidant Activity of Leaf and Bark Extracts of Combretumglutinosum
}

\author{
Ousmane Niass ${ }^{1}$, Amadou Diop ${ }^{2}$, Khadydiatou Thiam ${ }^{3}$, Rokhaya Géye ${ }^{4}$, Mariko Madani ${ }^{5}$, \\ Serigne Omar Sarr ${ }^{6}$, Bara Ndiaye ${ }^{7}$, Yérim Mbagnick Diop ${ }^{8}$

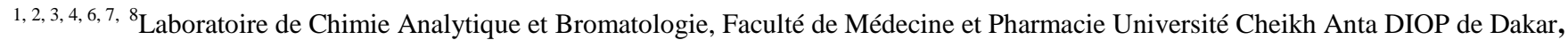 \\ BP 5005 Dakar-Fann Sénégal
}

${ }^{5}$ Laboratoire de chimie analytique, Faculté de pharmacie, Université Sciences techniques et de Technologie, B.P. 1805, Bamako, Mali

\begin{abstract}
The emergence of certain diseases such as cardiovascular diseases, diabetes, cancer, resulting from diet or environmental pollution makes relevant researches for therapeutic solutions among which, medicinal plants. It is in this perspective that we must place this study which is about the evaluation of the total polyphenol contents and the determination of the antioxidant activity of leaf and bark extracts of Combretum glutinosum.The results has shown the presence of polyphenols in all the extracts with a higher content in the extract by infusion of the leaves, which is $258,8 \mathrm{mg}$ gallic acid equivalent per gram. The study of the antioxidant activity has given low $I C_{50}$ values compared to those of the reference antioxidants, namely ascorbic acid and quercetin. The lowest IC $C_{50}$ value was obtained with fractions of the leaf infusion extract and was $0.122 \mu \mathrm{g} / \mathrm{ml}$ with the ethyl acetate fraction and $2,370 \mu \mathrm{g} / \mathrm{ml}$ with the aqueous fraction for the DPPH and ABTS tests respectively.
\end{abstract}

Keywords: antioxidant, polyphenols, quercetin, Combretum

\section{Introduction}

Over the last decades, special attention has been put on the development of plants with medicinal value as sources of natural bioactive substances. So thus, many studies are increasingly interested in the therapeutic effects of naturally occurring antioxidants due to the potential toxicological risks of synthetic antioxidant molecules [1].

However, the number of plants studied for pharmacological activities remains low. Only 144 out of 6763 families of species known to the wild have been studied, resulting in 939 approved drugs, 369 clinical trials, 119 preclinical drugs and 19,721 natural bioactive products [2].

Combretumglutinosum (Combretaceae) selected from an ethnobotanical survey, is a plant traditionally used in medicine in Senegal and particularly in Saloum. Methanolic extracts from these leaves and bark have already shown interesting antibacterial activities in vitro[3],[4] and alsoantiplasmodial activities with bark extracts [5]. The leaves of this plant are consumed as herbal tea next to Combretummicranthum and Vitexdoniana especially for breakfast or breaking of fasting. Despite their widespread use, the leaves of Combretum glutinosum have not been studied to determine their antioxidant potential

The aim of this study is to measure the total polyphenols and to assessthe antioxidant activity of the fractions of the aqueous and alcoholic extracts of the leaves and barks of Combretumglutinosum.

\section{Materials and Methods}

\subsection{Plant material}

The plant material used is madeof leaves and bark of Combretumglutinosum.

\subsection{Preparation of plant material}

The leaves and bark used in this study were harvested in Saloum (western Senegal). The plant material thus harvested were dried in the absence of light at ambient temperature and then ground into fine powder.

\subsection{Extraction and fractionation}

\subsubsection{Barks}

A test sample of $50 \mathrm{~g}$ of bark powder of Combretumglutinosumwere macerated with $500 \mathrm{ml}$ of hexane for 1 day. The mixture was filtered and the refined is dried before being re-macerated with $500 \mathrm{ml}$ of methanol for 5 days [3].

A test sample of $5 \mathrm{~g}$ of the dried methanol extract wascompletely dissolved in $250 \mathrm{ml}$ of pure water and then a liquid-liquid fractionation is carried out successively with the same volume of diethyl ether and chloroform. These three solutions are evaporated to dryness on a rotary evaporator before being used.

\subsection{2. leaves}

A test sampleof $50 \mathrm{~g}$ of leaf powder was infused into $500 \mathrm{ml}$ of boiling water. After cooling, the mixture was filtered and evaporated to dryness on a rotary evaporator under vacuum. 


\section{International Journal of Science and Research (IJSR) \\ ISSN (Online): 2319-7064}

Index Copernicus Value (2015): 78.96 | Impact Factor (2015): 6.391

A sample of $5 \mathrm{~g}$ of the dry extract obtained by infusion is dissolved in $250 \mathrm{ml}$ of water and then subjected to fractionation with ethyl acetate and chloroform successively.

The ethyl acetate, chloroform and aqueous fractions were evaporated to dryness and the residues obtained were used for the various tests.

\subsection{Determination of Total Polyphenols}

The dosage of polyphenol was made according to the methoddescribed by Vermerius and Nicholson in 2006 [6]. $0.1 \mathrm{ml}$ of aqueous extract solution at $1 \mathrm{mg} / \mathrm{ml}$ concentration was mixed with $2 \mathrm{ml}$ of a $2 \%$ sodium carbonate solution Freshly prepared, the whole is agitated by a vortex [6]. After five minutes, $100 \mu \mathrm{l}$ of the Folin-Ciocalteu reagent $(1 \mathrm{~N})$ are added to the mixture, the whole is left for 30 minutes at room temperature and the reading is performed against a blank using a spectrophotometer (Perkin Elmer, Lambda 800 Spectrophotometer) at $700 \mathrm{~nm}$. A calibration curve is carried out in parallel under the same operating conditions using gallic acid as a positive control. The results are denominatedin micrograms gallic acid equivalent per milligram of the dry plant extracts ( $\mu \mathrm{g} \mathrm{GAE} / \mathrm{mg})$.

\subsection{Evaluation of the antioxidant power}

\subsubsection{Experimental DPPH test protocol}

Anquantityof $4 \mathrm{mg}$ of DPPH powder was dissolved in 100 $\mathrm{ml}$ of ethanol and the solution obtained was kept away from light for $12 \mathrm{~h}$.

The antioxidant activity is measured by putting $0.8 \mathrm{ml}$ of the extract with $3.2 \mathrm{ml}$ of the DPPH solution into the test tubes to obtain final concentrations ranging from 1 to $9 \mu \mathrm{g} / \mathrm{ml}$ [7].

Ascorbic acid and quercetin, used as reference antioxidants, were also tested at the same concentrations using the same method.

The absorbance reading was made after 30 minutes at the spectrophotometer at the wavelength of $517 \mathrm{~nm}$ using ethanol as white. Three measurements of the absorbance were made.

\subsubsection{Experimental protocol of the ABTS test}

Anquantityof $38.40 \mathrm{mg}$ of ABTS is dissolved beforehand in $10 \mathrm{ml}$ of water.

Anquantityof $6.75 \mathrm{mg}$ of potassium persulfate is added thereafter. The mixture obtained was kept in the dark and at ambient temperature for 12 hours before use. This mixture is diluted with ethanol in order to obtain an absorbance of the order of 0.7 to $734 \mathrm{~nm}$.
The antioxidant activity was measured by mixing $0.8 \mathrm{ml}$ of the extract dissolved in ethanol with $3.2 \mathrm{ml}$ of the ABTS solution in order to obtain the concentrations varying from 1 to $9 \mu \mathrm{g} / \mathrm{ml}$.

Ascorbic acid and quercetin, used as reference antioxidants, were dissolved in ethanol and tested at the same concentrations. The absorbance reading was made after 2 minutes at the spectrophotometer at $734 \mathrm{~nm}$ using ethanol as white. Three absorbance measurements were performed for each concentration.

\subsubsection{Expression of results}

Inboth methods described above, the antioxidant activity was denominatedas the percentage inhibition (PI) of the absorbance of the radical which corresponds to:

$$
P I=\frac{A 0-A 1}{A 0} \times 100
$$

A0: absorbance of the solution of ABTS or pure DPPH A1: absorbance of the solution of ABTS or of DPPH ${ }^{\circ}$ after addition of the extract tested to a given concentration and after the reaction.

IC50 values are calculated from GraphPad Prism software (v5.0d, San Diego, CA) using a non-linear regression model using percent inhibition (PI) values.

\section{Results}

\subsection{Quantification of total polyphenols}

Table 1 shows the results obtained by a direct reading of the polyphenol contents of the extracts and fractions of the plant material. Average values are presented.

\begin{tabular}{|l|l|l|}
\hline & Extracts or fractions & Quantity(mg GAE/g) \\
\hline \multirow{5}{*}{ leaves } & Extract infusion & 258,8 \\
\cline { 2 - 3 } & Methanolic extract & 155,2 \\
\cline { 2 - 3 } & Chloroform fraction & 109 \\
\cline { 2 - 3 } & Ethyl acetate fraction & 266,4 \\
\cline { 2 - 3 } & Aqueous fraction & 267,7 \\
\hline \multirow{5}{*}{ barks } & Methanolic extract & 210,6 \\
\cline { 2 - 3 } & Chloroform fraction & 192,90 \\
\cline { 2 - 3 } & Fraction with ethyl ether & 49,4 \\
\cline { 2 - 3 } & Aqueous fraction & 232,1 \\
\hline
\end{tabular}

\subsection{Antioxidant activity}

\subsubsection{Percent inhibition with the DPPH method}

Table 2 shows the percent inhibition of aqueous and methanolic extracts, fractions (chloroform, ethyl acetate and water) of aqueous extracts of the leaves of Combretumglutinosum and the reference antioxidants (ascorbic acid and quercetin). 


\section{International Journal of Science and Research (IJSR) \\ ISSN (Online): 2319-7064 \\ Index Copernicus Value (2015): 78.96 | Impact Factor (2015): 6.391}

Table 2: Percentages of inhibition of extracts and fractions of the extract by infusion of leaves tested with DPPH

\begin{tabular}{|c|c|c|c|c|c|c|c|}
\hline$[\mu \mathrm{g} / \mathrm{ml}]$ & $\mathrm{MeOH}$ & E.I. & Fr.CHCl $_{3}$ & Fr.AE & Fr. $\mathrm{H}_{2} \mathrm{O}$ & Asc. Ac. & Quercétine \\
\hline 1 & 9,16 & 0,30 & 70,68 & 58,92 & 10,60 & 32,22 & 46,36 \\
\hline 2 & 16,85 & 3,95 & 81,69 & 86,05 & 16,52 & 45,79 & 66,79 \\
\hline 3 & 27,06 & 11,66 & 88,21 & 92,50 & 28,04 & 61,78 & 83,16 \\
\hline 4 & 37,75 & 30,84 & 93,60 & 92,82 & 53,67 & 72,92 & 90,02 \\
\hline 5 & 46,45 & 58,25 & 94,08 & 92,99 & 74,55 & 85,45 & 90,05 \\
\hline 6 & 54,53 & 73,69 & 94,29 & 93,10 & 84,85 & 89,33 & 90,55 \\
\hline 7 & 63,00 & 84,32 & 94,72 & 97,01 & 87,46 & 91,69 & 90,63 \\
\hline 8 & 72,04 & 87,06 & 98,24 & 97,85 & 88,24 & 93,24 & 90,67 \\
\hline 9 & 80,4 & 87,50 & 98,45 & 98,25 & 88,58 & 94,78 & 90,73 \\
\hline
\end{tabular}

MeOH: methanolextract; E.I: infusion extract; Fr CHCl3: chloroform fraction; Fr. AE: ethylacetate fraction; Fr. H2O: water fraction; AscAc: ascorbicacid

Table 3 represents the $\mathrm{IC}_{50} \mathrm{~s}$ corresponding to the various extracts.

Table 3: $\mathrm{IC}_{50}$ of extracts and fractions of infusate of leaves tested with DPPH

\begin{tabular}{|l|l|l|l|l|l|l|l|l|}
\hline Extracts & $\mathrm{MeOH}$ & E.I. & Fr.CHCl & Fr.EA & Fr. $\mathrm{H}_{2} \mathrm{O}$ & Ac. Asc. & Quercétine \\
\hline
\end{tabular}

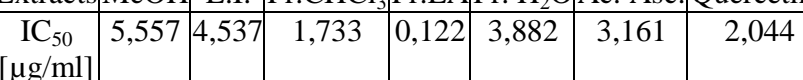

$\mathrm{MeOH}$ : methanolextract; E.I: infusion extract; Fr $\mathrm{CHCl}_{3}$ : chloroform fraction; Fr. E.A: ethylacetate fraction; Fr. $\mathrm{H}_{2} \mathrm{O}$ water fraction; AscAc: ascorbicacid

Table 4 shows the percent inhibition of methanol extract, fractions (chloroform, ethyl acetate and water) of methanolic extracts from the bark of Combretumglutinosum and the reference antioxidants (ascorbic acid and quercetin).

Table 4: Percentage of inhibition of the methanol extract of the bark and its fractions tested with DPPH

\begin{tabular}{|c|c|c|c|c|c|c|}
\hline$[\mu \mathrm{g} / \mathrm{ml}]$ & $\mathrm{MeOH}$ & $\mathrm{Fr} \mathrm{CHCl}_{3}$ & Fr.E.A & $\begin{array}{c}\text { Fr. } \\
\mathrm{H}_{2} \mathrm{O}\end{array}$ & $\begin{array}{c}\text { Asc. } \\
\text { Ac. }\end{array}$ & Quercétine \\
\hline 1 & 11,09 & 0,92 & 3,59 & 14,33 & 32,22 & 46,36 \\
\hline 2 & 18,34 & 31,11 & 11,62 & 34,19 & 45,79 & 66,79 \\
\hline 3 & 27,06 & 50,12 & 14,33 & 74,39 & 61,78 & 83,16 \\
\hline 4 & 35,65 & 76,21 & 36,05 & 88,11 & 72,92 & 90,02 \\
\hline 5 & 46,67 & 87,12 & 50,00 & 89,12 & 85,45 & 90,05 \\
\hline
\end{tabular}

\begin{tabular}{|l|l|l|l|l|l|l|}
\hline 6 & 52,87 & 87,79 & 63,46 & 89,26 & 89,33 & 90,55 \\
\hline 7 & 60,00 & 88,63 & 76,33 & 89,28 & 91,69 & 90,63 \\
\hline 8 & 67,17 & 88,77 & 82,60 & 89,29 & 93,24 & 90,67 \\
\hline 9 & 74,40 & 89,11 & 85,09 & 89,32 & 94,78 & 90,73 \\
\hline
\end{tabular}

$\mathrm{MeOH}$ : methanol extract; $\mathrm{CHCl}_{3}$ : chloroform fraction; $\mathrm{Fr}$. AE: ethyl acetate fraction; Fr. $\mathrm{H}_{2} \mathrm{O}$ : water fraction; Ac. Asc: ascorbic acid

Table 5 represents the $\mathrm{IC}_{50} \mathrm{~s}$ corresponding to the various extracts.

Table 5: $\mathrm{IC}_{50}$ of the methanolic extract of the bark and its fractions tested by DPPH

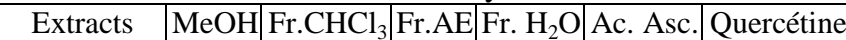

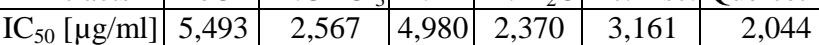

$\mathrm{MeOH}$ : methanol extract; $\mathrm{CHCl}_{3}$ : chloroform fraction; Fr. AE: ethyl acetate fraction; Fr. $\mathrm{H}_{2} \mathrm{O}$ : water fraction; Ac. Asc: ascorbic acid

\subsubsection{Percent inhibition with the ABTS method}

Table 6 shows the percentage inhibition of aqueous and methanolic extracts, fractions (chloroform, ethyl acetate and water) of aqueous extracts of the leaves of Combretumglutinosum and the reference antioxidants (ascorbic acid and quercetin).

Table 6: Percentage of inhibition of the extracts and fractions of the extract by infusion of leaves tested with ABTS

\begin{tabular}{|c|c|c|c|c|c|c|c|}
\hline$[\mu \mathrm{g} / \mathrm{ml}]$ & $\mathrm{MeOH}$ & E.I. & Fr.CHCl $_{3}$ & Fr. E.A & Fr. $\mathrm{H}_{2} \mathrm{O}$ & Asc. Ac. & Quercétine \\
\hline 1 & 36,77 & 64,30 & 58,29 & 66,62 & 66,68 & 76,96 & 93,49 \\
\hline 2 & 53,67 & 77,30 & 64,84 & 77,60 & 76,09 & 74,27 & 99,41 \\
\hline 3 & 72,58 & 87,00 & 69,53 & 89,88 & 86,34 & 76,63 & 99,28 \\
\hline 4 & 87,12 & 94,64 & 76,25 & 95,05 & 93,46 & 87,02 & 99,36 \\
\hline 5 & 99,09 & 98,66 & 83,28 & 99,49 & 97,83 & 93,85 & 99,50 \\
\hline 6 & & 99,24 & 87,28 & 99,50 & 99,35 & 95,17 & 99,61 \\
\hline 7 & & 99,30 & 92,90 & 99,52 & 99,39 & 99,63 & 99,62 \\
\hline 8 & & 99,38 & 94,55 & 99,55 & 99,41 & 99,77 & 99,64 \\
\hline 9 & & 99,58 & 95,07 & 99,81 & 99,43 & 99,83 & 99,75 \\
\hline
\end{tabular}

MeOH: methanolextract; E.I: infusion extract; $\mathrm{Fr} \mathrm{CHCl}_{3}$ : chloroform fraction; Fr. E.A: ethylacetate fraction; Fr. $\mathrm{H}_{2} \mathrm{O}$ : water fraction; AscAc: ascorbicacid

Table 7 represents the $\mathrm{IC}_{50} \mathrm{~s}$ corresponding to the various extracts.
Table 7: $\mathrm{IC}_{50}$ of extracts and fractions of infusion extract of leaves tested by ABTS

\begin{tabular}{|l|l|l|l|l|l|}
\hline$\mu \mathrm{g} / \mathrm{ml}]$ & $\mathrm{MeOH}$ & I.T & Fr.CHCl $_{3}$ Fr.E.A Fr. $\mathrm{H}_{2} \mathrm{O}$ & Ac. Asc. Quercétine \\
\hline
\end{tabular} \begin{tabular}{|l|l|l|l|l|l|l|l|}
$\mathrm{IC}_{50}$ & 3,683 & 2,349 & 4,638 & 2,371 & 2,624 & 4,164 & 0,3351 \\
\hline
\end{tabular}

$\mathrm{MeOH}$ : methanolextract; E.I: infusion extract; $\mathrm{Fr} \mathrm{CHCl}_{3}$ : chloroform fraction; Fr. E.A: ethylacetate fraction; Fr. $\mathrm{H}_{2} \mathrm{O}$ water fraction; AscAc: ascorbicacid

Table 8 shows the percentage inhibition of methanol extract, chloroform, ethyl acetate and water fractions of methanolic

\section{Volume 6 Issue 7, July 2017 www.ijsr.net}




\section{International Journal of Science and Research (IJSR) \\ ISSN (Online): 2319-7064 \\ Index Copernicus Value (2015): 78.96 | Impact Factor (2015): 6.391}

extracts from the bark of Combretumglutinosum and the reference antioxidants (ascorbic acid and quercetin).

Table 8: Percentage inhibition of the methanol extract of the bark and its fractions tested with ABTS

\begin{tabular}{|c|c|c|c|c|c|c|}
\hline$[\mu \mathrm{g} / \mathrm{ml}]$ & $\mathrm{MeOH}$ & Fr.CHCl $_{3}$ & Fr.EA & Fr. $\mathrm{H}_{2} \mathrm{O}$ & Asc. Ac. & Quercétine \\
\hline 1 & 59,38 & 65,06 & 55,82 & 68,73 & 76,96 & 93,49 \\
\hline 2 & 67,49 & 74,57 & 59,01 & 80,74 & 74,27 & 99,41 \\
\hline 3 & 74,48 & 83,14 & 61,55 & 91,56 & 76,63 & 99,28 \\
\hline 4 & 81,56 & 91,11 & 65,45 & 97,66 & 87,02 & 99,36 \\
\hline 5 & 85,47 & 96,17 & 67,88 & 99,49 & 93,85 & 99,50 \\
\hline 6 & 90,79 & 98,94 & 68,98 & 99,51 & 95,17 & 99,61 \\
\hline 7 & 95,43 & 99,32 & 72,56 & 99,53 & 99,63 & 99,62 \\
\hline 8 & 97,47 & 99,34 & 75,34 & 99,58 & 99,77 & 99,64 \\
\hline 9 & 99,04 & 99,68 & 76,00 & 99,94 & 99,83 & 99,75 \\
\hline
\end{tabular}

$\mathrm{MeOH}$ : methanol extract; $\mathrm{CHCl}_{3}$ : chloroform fraction; Fr. AE: ethyl acetate fraction; Fr. $\mathrm{H}_{2} \mathrm{O}$ : water fraction; Ac. Asc: ascorbic acid

Table 9 shows the $\mathrm{IC}_{50} \mathrm{~s}$ corresponding to the various extracts.

Table 9: $\mathrm{IC}_{50}$ of the methanolic extract of the barks and its fractions tested by ABTS

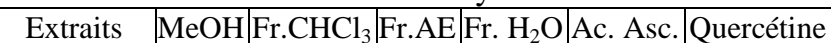
\begin{tabular}{|l|l|l|l|l|l|l|}
\hline $\mathrm{IC}_{50}[\mu \mathrm{g} / \mathrm{ml}]$ & 4,851 & 2,842 & 12,11 & 2,224 & 4,164 & 0,3351 \\
\hline
\end{tabular}

$\mathrm{MeOH}$ : methanol extract; $\mathrm{CHCl}_{3}$ : chloroform fraction; Fr. AE: ethyl acetate fraction; Fr. $\mathrm{H}_{2} \mathrm{O}$ : water fraction; Ac. Asc: ascorbic acid

\section{Discussion}

Numerous scientific studies have attributed the antioxidant power of plant extracts to the presence of polyphenols in plant matter [8], highlighting the importance of quantifying these secondary metabolites.

In this study, the polyphenols are quantified using the FolinDenis reagent consisting of a mixture of phosphomolybdic acid, sodium tungstate and phosphoric acid. It is reduced during the oxidation of the phenols to a mixture of blue oxides of tungsten and molybdenum [9].

The results showed that the aqueous extract $(258.8 \mathrm{mg}$ $\mathrm{AGE} / \mathrm{g}$ ) is richer in polyphenols than that on methanol (155.2 $\mathrm{mg} \mathrm{GAE} / \mathrm{g}$ ). For the fractions of the infusate, the polyphenols are more present in the ethyl acetate fraction and in the aqueous fraction (Table 1). with regard to theextracts and bark fractions, the polyphenols are more present in the aqueous fractions (232.10 mg GAE/g) and chloroform (192.90 mg EGA/g). The lowest content was found in the ethyl ether fraction (49.4 $\mathrm{mg} \mathrm{GAE} / \mathrm{g}$ ).

These high levels of polyphenols presume an interesting antioxidant activity of the extracts and fractions of barks and leaves which we sought to determine by the ABTS and DPPH methods.

As per the DPPH method, the infusion extract of leaves is more reducer than the methanol extract. In the same way, the ethyl acetate fraction was found to be more reductive than the chloroform fraction (Table 2). $\mathrm{IC}_{50}$ values lower than those of the reference antioxidants were obtained. In fact, they were in the order of $0.122 \mu \mathrm{g} / \mathrm{ml}$ for the ethyl acetate fraction and $1.733 \mu \mathrm{g} / \mathrm{ml}$ for the chloroform fraction, while those of the reference antioxidants, namely quercetin and ascorbic acid, were $3.161 \mu \mathrm{g} / \mathrm{ml}$ and $2.04 \mu \mathrm{g} / \mathrm{ml}$ (Table 3), respectively.

With the bark, the chloroform and aqueous fractions are the most inhibitory (Table 4) with respective $\mathrm{IC}_{50}$ values of $2.567 \mu \mathrm{g} / \mathrm{ml}$ and $2.70 \mu \mathrm{g} / \mathrm{ml}$ higher than those of ascorbic acid but lower than that of quercetin (Table 5).

The antioxidant power tested with the ABTS method showed that the leaf infusion extract is more antioxidant than the methanol extract (Table 6). It has also been demonstrated that among the fractions obtained from this extract by infusion that of ethyl acetate $\left(\mathrm{IC}_{50}\right.$ of $\left.2.37 \mu \mathrm{g} / \mathrm{ml}\right)$ is more reductive followed by the aqueous fraction $(2.62 \mu \mathrm{g} / \mathrm{ml})($ Table 7$)$. These $\mathrm{IC}_{50} \mathrm{~s}$ are markedly lower than those of ascorbic acid $(4.16 \mu \mathrm{g} / \mathrm{ml})$ and quercetin $(0.33$ $\mu \mathrm{g} / \mathrm{ml})$.

As per the ABTS method, the aqueous and chloroform fractions of Combretum glutinosum peel extracts showed the most interesting antioxidant potency (Table 8) with $\mathrm{IC}_{50}$ values of $2.22 \mu \mathrm{g} / \mathrm{ml}$ and $2.84 \mu \mathrm{g} / \mathrm{ml}$ respectively. These values are lower than those of ascorbic acid (Table 9).

The results obtained fromall the tests has shown a proportional relationship between the antioxidant power and the total polyphenol content of the extracts and subsequently confirm previous studies [8]. Of the two parts of the plant, the leaves have an antioxidant activity greater than that of the bark, but also the extract by infusion is more antioxidant than the alcoholic extract, which is crucial since the leaves are consumed by infusion for most of the time.

Many studies have shown the importance of polyphenols in the prevention of cancer [10]. Indeed, this explains the high consumption of tea (Camelliasinensis) because of its polyphenols [11]. In Jo studies, tea (Camelliasinensis) has a much lower antioxidant power than Combretumglutinosum by comparing the $\mathrm{IC}_{50}$ values of the same types of extracts with that of ascorbic acid used as a reference in both cases [12] using the same methods of studying antioxidant activity as those in our study.

\section{Conclusion}

Combretumglutinosum is a widely used plant in Senegal both for its medicinal virtues and for its qualities as food. The interesting results from this study validate the traditional use of this plant. At the same timeit highlights its therapeutic interest in the prevention of certain diseases (cancer). This study has shownthat the exploration of traditional Senegalese pharmacopoeia couldhelp to overcomemany health issuesand alsoprovide economic exploitation of local flora.

\section{References}

[1] El-Haci, I.A. , F. Atik-Bekkara, A. Didi, M. Gherib, M.A. Didi. Teneurs en polyphénols et pouvoir

\section{Volume 6 Issue 7, July 2017 www.ijsr.net}




\section{International Journal of Science and Research (IJSR) \\ ISSN (Online): 2319-7064 \\ Index Copernicus Value (2015): 78.96 | Impact Factor (2015): 6.391}

antioxydant d'une plante médicinale endémique du Sahara algérien; Pharmacognosie 2012, Phytothérapie (C) Springer-Verlag France 2012 DOI 10.1007/s10298012-0726-X

[2] Zhu F., Chu Qin, Lin Tao, Xin Liu, Zhe Shi, Xiaohua Ma, JiaJia, Ying Tan, Cheng Cui, Jinshun Lin, Chunyan Tan, Yuyang Jiang and Yuzong Chen: Clustered patterns of species origins of nature-derived drugs and clues for future bioprospecting Proceedings. National Academy of Sciences (PNAS) (August 2, 2011) vol. 108 no. 31 12943-12948

[3] Niass, O., Sarr, S. O., Diop, A., Diop, A., \& Diop, Y. M. Etude in vitro de l'activité antibactérienne de quelques plantes utilisées en médecine traditionnelle locale au Saloum (Sénégal). In vitro study of antibacterial activity of some plants used in traditional medicine in local Saloum (Senegal) ScienceLib Editions Mersenne: 2015 Volume 7, N ${ }^{\circ} 150801$ ISSN 21114706.

[4] Niass, O., Sarr, S. O., Diop, A., Diop, A., \& Diop, Y. M. (2016). In Vitro Assessment of Antimicrobial Activity of Combretum Glutinosum Leaves Extracts (Combretaceae). Journal of Chemical, Biological and Physical Sciences (JCBPS), 6(2), 603.

[5] Niass, O., Sarr, S. O., Dieye, B., Diop, A., \& Diop, Y. M. (2016). In Vitro Assessment of the Antiplasmodial Activity of Three Plants Extracts Used In Local Traditional Medicine In Saloum (Senegal). European Scientific Journal, 12(12).

[6] Vermerris W, Nicholson R (2006) Isolation and identification of phenolic compounds. In: Phenolic compound biochemistry. Springer, Dordrecht New York, pp. 35-62

[7] Molyneux, P. (2003). The use of the stable free radical diphenylpicrylhydrazyl (DPPH) for estimating antioxidant activity. [artikel]. UK : Polymer Chemistry, Macrophile Associates.

[8] Quideau, S., Deffieux, D., Douat-Casassus, C., \&Pouysegu, L. (2011). Plant polyphenols: chemical properties, biological activities, and synthesis. AngewandteChemie International Edition, 50(3), 586621.

[9] Boizot N, Charpentier JP (2006) Méthode rapide d'évaluation du contenu en composés phénoliques des organes d'un arbre forestier, INRA - Amélioration, génétique et physiologie forestières, laboratoire d'analyses biochimiques. Le Cahier des Techniques de l'Inra, pp. 79-82

[10] Lambert, J. D., \& Elias, R. J. (2010). The antioxidant and pro-oxidant activities of green tea polyphenols: a role in cancer prevention. Archives of biochemistry and biophysics, 501(1), 65-72.

[11] Celik, M.Yusuf, CelikFatma. Turkish Tea: The Only Tea Washed with Snow that Snow Falls on :International Journal of Basic and Clinical Studies (IJBCS) 2014;3(2): 1-15

[12] JO, Young-Hong, YUK, Hyun-Gyun, LEE, Jong-Hwa, et al. Antioxidant, tyrosinase inhibitory, and acetylcholinesterase inhibitory activities of green tea (Camellia sinensis L.) seed and its pericarp. Food Science and Biotechnology, 2012, vol. 21, no 3, p. 761768.

Volume 6 Issue 7, July 2017 www.ijsr.net 